56 Hendi Hendarto : The Effect of Bone Marrow Transplantation on Oocyte-Granulosa Cell Interaction

\title{
The Effect of Bone Marrow Transplantation on Oocyte-Granulosa Cell Interaction and Follicular Development of Cisplatin-Induced Ovarian Failure in Rat
}

\author{
Hendi Hendarto $^{1 *}$, Mohammad Ferry Komarhadi ${ }^{1}$, Erva Darmawanti ${ }^{1}$, Widjiati ${ }^{2}$, \\ Suhatno ${ }^{1}$, Fedik Abdul Rantam ${ }^{3}$ \\ ${ }^{1}$ Department of Obstetrics and Gynecology, Faculty of Medicine, Universitas Airlangga, Surabaya, \\ ${ }^{2}$ Laboratory of In Vitro Fertilization, Faculty of Veterinary Medicine, Universitas Airlangga, Surabaya, \\ Indonesia. \\ ${ }^{3}$ Stem Cell Research and Development Center, Universitas Airlangga, Surabaya, Indonesia. \\ *Corresponding author: hndhendy@yahoo.com
}

\begin{abstract}
Introduction: Chemotherapy has cytotoxic effect that induces follicular damage and abnormal folliculogenesis leads to ovarian failure. Two crucial growth factors in abnormal folliculogenesis, Growth Differentiation Factor-9 (GDF-9) and Kit-Ligand, will be disrupted and affect follicular development. In this study, we evaluate whether bone marrow transplantation (BMT) has a role on oocyte-granulosa cell interaction by analyzing GDF-9 and Kit-Ligand expressions and also follicular development by analyzing primordial, primary, secondary and graafian follicles of cisplatin-induced ovarian failure in rat. Material and method: Forty eight rats were divided into three groups: control, cisplatin and cisplatin + BMT. Ovarian failure was induced by administration of intraperitoneal cisplatin $5 \mathrm{mg} / \mathrm{kg}$ body weight for 1 week. BMT 2 x107 cells were injected through rat tail vein after cisplatin administration. Bone marrow was isolated from rat femur and characterized by CD44(+), CD45(-), CD105(+). Immunohistochemistry examinations for ovarian GDF-9, Kit-Ligand and follicle development evaluation were performed after 2 weeks of BMT injection. Results: The expressions of Kit-ligand among three groups by ANOVA were significant different $(\mathrm{p}=0.00)$, whereas by Post Hoc: cisplatin group lower than control group $(\mathrm{p}=0.00)$; cisplatin + BMT group higher than cisplatin group ( $\mathrm{p}=0.00)$; and no significant different between control group and cisplatin + BMT group ( $\mathrm{p}=0.955)$. The expressions of GDF-9 by Kruskal Wallis showed significant different $(\mathrm{p}=0.00)$ among three groups whereas cisplatin + BMT group higher than cisplatin group and control group. In cisplatin + BMT group the number of primordial, primary, secondary and graafian follicles were higher than those in cisplatin group; but were lower than those in control group $(p=0.000)$. Positive Paul Kart Horan $(\mathrm{PKH})$ labeling was seen in cisplatin + BMT group only. Conclusion: In cisplatin-induced ovarian failure in rat, bone marrow transplantation may improve oocytegranulosa cell interaction and follicular development.
\end{abstract}

Key words: Bone Marrow, GDF-9, Kit-ligand, follicle, Ovarian failure 


\section{INTRODUCTION}

Chemotherapy is one part of cancer therapy with the aim of suppressing the growth of the disease and improves the quality of life of the patients (WHO, 2008). The use of chemotherapy has significantly increased the cure rate in cancer patients in young age $(\mathrm{Su}, 2011)$. However, some side effects, such as ovarian failure and infertility, may occur. Ovarian failure is a consequence of chemotherapy in cancer patients due to cytotoxic effects that will damage the granulosa cells and induces acute damage in ovarian follicle growth so that folliculogenesis disruption may take place (Melrow and Nugent, 2001; Dolmans et al., 2005). Various methods of treatment have been made to overcome ovarian failure due to chemotherapy, such as stem cell therapy. However, to date the effect of stem cell transplantation to repair folliculogenesis disruption in ovarian failure remains a debate.

Folliculogenesis is a process of ovarian follicles growth and development, which is the interaction of oocyte and granulosa cells with

\section{MATERIALS AND METHODS}

Animal

This study was an experimental laboratory study with a double blind randomized design. The population in this study were female rats (wistar strain Rattusnovergicus) obtained from the laboratory animal unit of the 'Faculty of Veterinary Medicine, Airlangga University. Before starting, female rats were caged for a week at room temperature and given with ad libiturn resulting in mature and fertilizable oocytes. There are two crucial growth factors that play a role in the interaction of oocyte and granulosa cells, namely Growth Differentiation Factor-9 (GDF-9) derived from oocyte and Kit-Ligand produced from granulosa cells (Rajkovic et al., 2006; Joyce et al., 2000; Hendarto, 2012). In abnormal folliculogenesis, the interaction of both growth factors could-disturb the growth of follicles in the ovaries. The use of bone marrow mesenchymal stem cells, which have the ability to regenerate itself and differentiate into other tissue cells, has been tried for regeneration therapy of various diseases. Our current study aimed to evaluate the effect of allogeneic bone marrow transplantation on the oocyte-granulosa cell interaction by analyzing the expression of GDF9 and Kit-Ligand and the description of follicular development by analyzing the number of primordial, primary, secondary, and graafian follicles in cisplatin-induced ovarian failure in rat.

diet. Forty-eight rats that met the inclusion and exclusion criteria with homogeneous characteristics in terms of mean age and body weight were divided into three groups. The first group was the control group, injected with $0.9 \%$ $\mathrm{NaCl}$ intraperitoneum, the second group was the group of rat models with ovarian failure, administered with cisplatin $5 \mathrm{mg} / \mathrm{kg}$ 
intraperitoneally for 1 week, and the third group was the group of rat models with ovarian failure, which, after receiving cisplatin, were administered with bone marrow stern cell transplantation (BMT) for 2 weeks.

Isolation, culture and transplantation of bone marrow stem cells.

Bone marrow aspirates were collected from donor rat femoral bone with a local anesthetic. Each aspirate was mixed and coated with Ficoll and then centrifugated in $1600 \mathrm{rpm}$ for 15 minutes. The 'huffy coat' located on Ficoll-PBS was collected with a Pasteur pipette. Cells were placed on 5 or $10 \mathrm{~cm}^{2}$ plate, followed by cell incubation at $37^{\circ} \mathrm{C}$ with humidity of $5-\% \mathrm{CO}_{2}$ for 24 hours.
Examination with microscope was done every day and every 3 days the cells were washed with 5 or $10 \mathrm{ml}$ PBS and $10 \mathrm{ml}$. CCM was added until the cells were became confluent between $60-80 \%$.

Bone marrow as many as $2 \times 10^{7}$ cells were injected through recipient rat tail intravenously 1 week after intraperitoneal cisplatin administration (Rantam et al., 2009)..

GDF-9, Kit-ligand and follicular development evaluation

Two weeks after bone marrow transplantation the ovarian expression of GDF-9 and Kit-Ligand were evaluated with immunohistochemical method by quantity of cells that express in ten views. Anti GDF-9 and Kit-Ligand antibody was purchased from Abeam.' Primordial, primary, secondary, and graafian follicles development were

\section{RESULT}

This research was conducted between May and August 2019 in Experimental Animal Cage, Veterinary Pathology Laboratory, Faculty of Veterinary Medicine, University of Airlangga Surabaya Two weeks after BMT administration, the rats were sacrificed and subsequently the

\section{GDF-9 expression}

Immunohistochemical analysis of the three groups of rat ovaries showed a positive signal for GDF-9 protein. Analysis of GDF-9 evaluated using haematoxillineosin staining method in three groups of rats above. All data were analyzed using statistical SPSS/PC computer program for windows. All three groups' data were compared using the ANOVA test. The differences are considered to be statistically significant if $\mathrm{p}<0,05$.

ovarian tissue was evaluated. Previously, characterization had been carried out to bone marrow stem cell preparation with the CD44(+), CD45(-), CD-1_05 (+) which indicated mesenchymal stem cells

expression in 'all three groups were as follows: control $(14.53 \pm 1.42)$; cisplatin $(5.33 \pm 1.76)$ and cisplatin + BMT group (15.91 \pm 0.69$)$, there were 
significant differences in the three groups above $(\mathrm{p}=0.00)$ by Kruskal Wallis. The count was in accordance with the results of immunohistochemical staining images marked in brown colour on the immune reactive cells that

\section{Kit-Ligand expression}

Immunohistochemical analysis in all three groups of rat ovaries also showed a positive signal for Kit-Ligand protein. Analyses of KitLigand expression in all three groups were as follows: control $(20.22 \pm 2.14)$, cisplatin $(12.27 \pm$ $2.88)$ and cisplatin + BMT group (20.26 \pm 1.14$)$. There were significant differences in the three groups above $(\mathrm{p}=0.00)$ by ANOVA; whereas by Post Hoc: cisplatin group lower than control group ( $\mathrm{p}=0.00)$; cisplatin + BMT group higher

\section{Follicular development}

The process of follicular development is characterized by the development of primordial primary, secondary, graafian follicles. In this study the cisplatin group showed the number of primordial $(4.31 \pm 1.19)$, primary $(3.81 \pm 1.22)$, secondary $(2.87 \pm 0.95)$, and graafian follicles $(0.37 \pm 0.69)$ were lower than those in control group $(6.12 \pm 1.20),(4.93 \pm 1.61),(4.25 \pm$ $0.77)$ and $(5.81 \pm 1.37)(\mathrm{p}=0.000)$.

\section{DISCUSSION}

As we all know there is dependence interaction between oocyte and granulosa cells. Oocytes secrete factors that regulate the development of granulosa cells surrounding the oocytes in the express the protein GDF-9. The lowest expression of GDF-9 was found in cisplatin administration, whereas the highest expression was found in cisplatin + BMT group (Figure 1)

than cisplatin group ( $\mathrm{p}=0.00)$; and no significant different between control group and cisplatin + BMT group $(p=0.955)$. The results above were in accordance with immunohistochemical staining images marked in brown colour on the immunoreactive cells that express Kit-Ligand protein. The lowest expression of Kit-Ligand was found in cisplatin administration, whereas the highest expression was found in in cisplatin + BMT group (Figure 2).

In cisplatin + BMT group, the number of primordial $(5.31 \pm 1.30)$, primary $(4.37 \pm 0.88)$, secondary $(3.62 \pm 0.71)$ and graafian follicle $(2.75$ \pm 0.85 ) were higher than those in cisplatin and control group (Figure 3). In this study, Paul Karl Horan $(\mathrm{PKH})$ cell labeling was also conducted. Subsequently, signal identification was carried out after BMT, and positive PKH labeling was seen in cisplatin + BMT group, while negative result was found in cisplatin group (Figure 4).

ovarian follicle. Granulosa cells secrete KitLigand to regulate oocyte growth and development. The main candidate molecules secreted by the oocyte is 

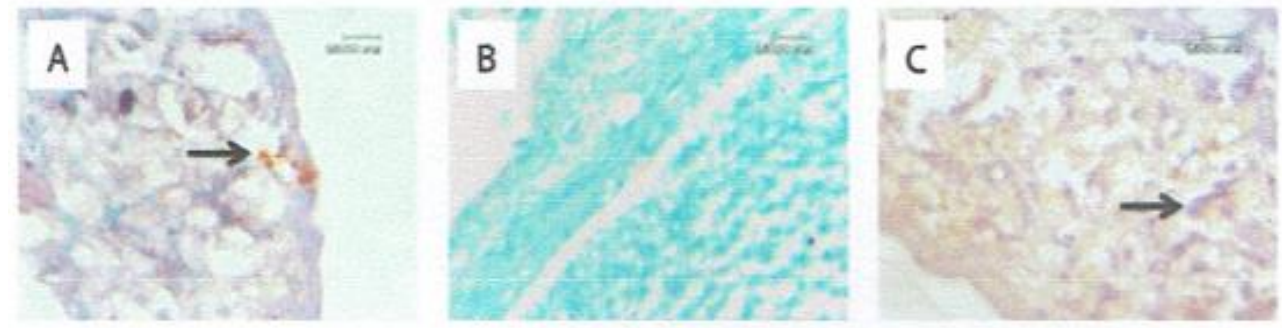

Figure 1: Immunohistochemical staining for GDF-9 in rat ovarium of (A) control, (B) cisplatin and (C) cisplatin+BMT groups show the immunoreactive cells with brown colour.
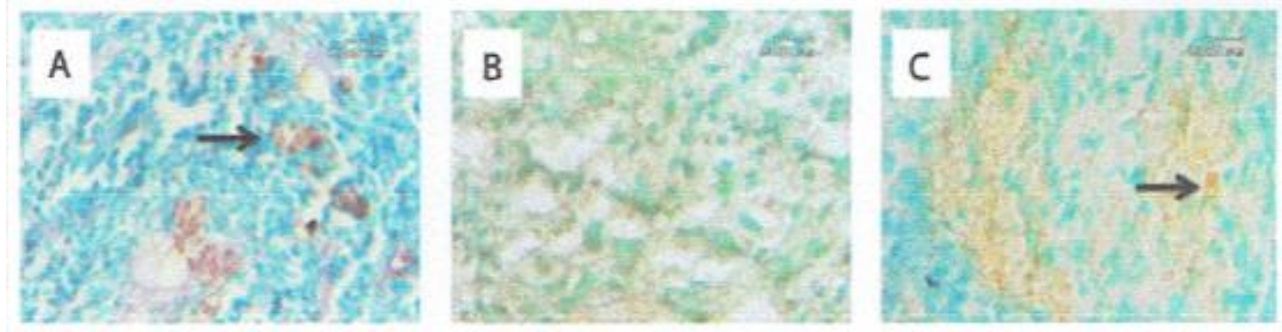

Figure 2: Immunohistochemical staining for Kit Ligand in rat ovarium (A) control, (B) cisplatin and (C) cisplatin+BMT groups show the immunoreactive cells with yellow to brown colour.
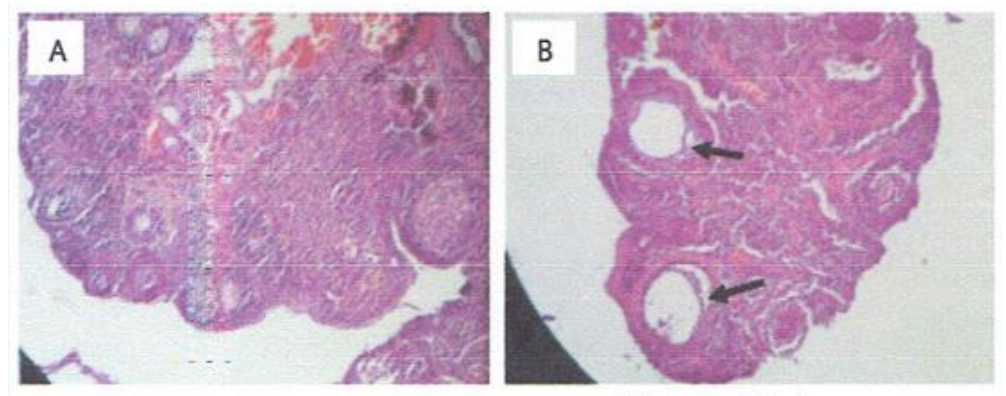

1000x magnification

Figure 3: Haematoxillin eosin staining for follicular development in (A) cisplatin and (B) cisplatin+BMT group. Graafian have seen in cisplatin+BMT group but not in cisplatin group.
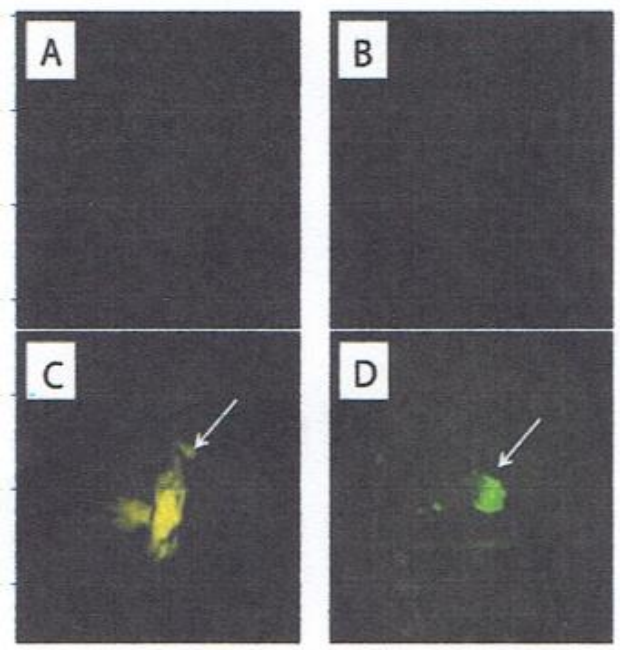

Figure 4: PKH for fluorescent cell labeling in $(\mathrm{A} \& \mathrm{~B})$ cisplatin and $(\mathrm{C} \& \mathrm{D})$ cisplatin+BMT group 
GDF-9, a growth factor from the family TGF- $\beta$ produced by oocytes (Joyce et al., 2000). Filho suggested that GDF-9 is a crucial factor in folliculogenesis and fertility, and it was proved that the expression of GDF-9 decreases in women with polycystic ovary indicated by the disturbance oocyte growth and differentiation (Teixeira et al., 2001).This study revealed the difference in the expression of GDF-9 in the three groups. The expression of GDF-9 in the cisplatin group $(5.33 \pm 1.76)$ was lower compared to that in control group $(14.53 \pm 1.42)$, which means that there has been a disturbance in folliculogenesis due to disrupted production of GDF-9, allegedly due to apoptosis in the oocyte resulting from cisplatin chemotherapy

Cisplatin 'is a chemotherapy drug from the class of alkylating agents from platinum compounds used for the treatment of ovarian, breast and bladder cancers. Once administered, cisplatin will diffuse inside the cell which then binds to DNA, thereby preventing DNA transcription and replication. Cis-DDP (Diammine Dichloro Platinum) binding on $\mathrm{g}$ (genomic) DNA contained in the nucleus is responsible for the mechanism and will trigger cell death/apoptosis (Turkyilmaz et al., 2008). In group 3 that received BMT GDF-9 expression was higher $(15.91 \pm 0.69)$ than cisplatin group (5.33 \pm 1.76). This result suggests that BMT produced therapeutic effects, suspected in the form of immediate termination of apoptotic rate, possibly through the improvement of pro-and antiapoptotic protein ratio, thereby increasing the expression of GDF-9. In addition, this extragonadal BMT releases progenitor germ cells into the circulation and then it was "homing" to the ovaries and engrafted within the follicle. Another possible mechanism may be the transformation to improve the microenvironment in ovarian follicles (Johnson, 2007).

This study showed the data on the difference of Kit-Ligand expression in the three groups above. Kit-Ligand expression in cisplatin group $(12.27 \pm 2.88)$ was lower than that in control group $(20.22 \pm 2.14)$, which means that there has been damage or apoptosis in granulosa cell due to intraperitoneal cisplatin administration, resulting in low expression of Kit-Ligand. In group 3 that received BMT, Kit• Ligand expression $(20.26 \pm 1.14)$ was higher than cisplatin group $(12.27 \pm 2.88)$. These results suggest that BMT provides the same therapeutic effect on granulosa cells and oocytes in the form of improved ratio of pro- and anti-apoptotic proteins. In addition, as in the oocyte, BMT progenitor germ cell was "homing" to the ovaries and engrafted in the follicle, thus improving the expression of Kit-Ligand.

Further results in this study showed that the number of follicular development in the cisplatin group in the form of primordial $(4.31 \pm 1.19)$, primary $(3.81 \pm 1.22)$, secondary $(2.87 \pm 0.95)$ and graafian $(0.37 \pm 0.69)$ follicles were lower than the control group, which was $(6,12 \pm 1.20),(4 ., 93 \pm 1.61),(4.25 \pm 0.77)$ and $(5.81 \pm 1.37)$, respectively. Follicle is the functional unit of the female reproductive organs, consisting of 3 cells: granulosa, theca cell and oocyte. Folliculogenesis is a growth and 
development process involving endocrine and molecular interactions between the 3 cells, particularly between oocyte and granulosa cells with the final result mature and fertilizable oocyte (Rajkovic et al., 2006). These results confirm that the administration of cisplatin will damage oocyte and granulosa cells and interfere with secreted growth factor. The subsequent result is the disrupted interaction of oocyte and granulosa cells and in folliculogenesis process, resulting in the reduction of a significant number of follicular development in the group receiving cisplatin Therefore, the number of follicular development in BMT group was higher than cisplatin group. This situation means that the therapeutic effects of BMT successfully repair damaged oocyte

\section{REFERENCES}

Dolmans MM, Demylle D, Madrid BM, Donnez J. 2005. Efficacy of in vitro fertilization after chemotherapy. Fertil Steril 83: 897901.

Hendarto H. 2012. Pathomechanism of Infertility in Endometriosis in: Chaudhury $\mathrm{K}$ and Chakravarty B. Endometriosis-Basic Concepts and Current Research Trends. Intech, Croatia, 343-354.

Johnson J. 2007. Stem cell support of ovary Function and Fertility. In: Simon c, pellicer A. Stemcell in Human Reproduction: Basic science and therapeutic Potential. Informa Healthcare $21-44$. and granulosa cells and their growth factor production. The final result is folliculogenesis process improvement, as reflected by the higher number of follicular development in BMT group. The conclusion of this study is that in cisplatininduced ovarian failure in rat, bone marrow transplantation may improve oocyte-granulosa cell interaction and follicular development. Further study is required to confirmation that result, with some improvement of methodology such as: using GFP to trace the BMT in cells, add sham group (PBS and BMT) as a control, perform ELISA to confirm enhanced GDF-9 secretion and exploration the optimal dose of BMT.

Joyce IM, Clark AT, Pendola FL, Eppig JJ. 2000. Comparison of recombinant Growth Differentiation Factor-9 and Oocyte Regulation of KIT Ligand Messenger Ribonucleic Acid Expression in Mouse Ovarian Follicles. Biol Reprod 63: 16691675.

Meirow D, Nugent D. 2001. The effect of radiotherapy and chemotherapy on female reproduction. Hum Reprod Update 7: 535-543.

Rajkovic A, Pangas SA, Matzuk MM. 2006. Follicular Development: Mouse, sheep and human models, In: Neill JD, Knobil and Neill's Physiology of Reproduction, (3rdedn.), 383-424. 
Rantam FA, Ferdiansyah, Nasronudin, Purwati. 2009. Isolation and culture of stem cells from human bone marrow, In: Stem Cell exploration, Methods of Isolation and culture, (1stedn), Surabaya: Airlangga University Press, 11-25.

Su HI. 2011. Measuring ovarian function after cancer treatment. Menopausal Medicine 19: S1-S4.

Teixeira Filho FL, Baracat EC, Lee TH, Suh CS, Matsui M, et al. 2001. Aberrant expression of growth differentiation factor-9 in oocytes of women with polycystic avary syndrome. J. Clin. Endoainol Metab 87:1337-1344.

Turkyilmaz c, Bulent O, mahmut TO, Tolga A, Cem B, et al. 2008. Effect of Paclitaxel and cisplatin on ovarian reserves in rats. Erciyes Typ Dergisi 30: 449-498.

WHO. 2008. Diagnostic and treatment. Cancer control knowledge into action WHO guide for effective programmes. WHO Library cataloguing-in-publication data, Switzerland. 